\title{
The women knowledge, attitude, and perceptions of pre-eclampsia and eclampsia in Madagascar
}

\author{
Randriamahavonjy Romuald ${ }^{1}$, Tanjona A. Ratsiatosika ${ }^{2 *}$, Rakotonirina A. Martial ${ }^{2}$, \\ Rainibarijaona A. Lantonirina ${ }^{2}$, Rakotonirina Ando-Miora ${ }^{2}$, \\ Andrianampanalinarivo H. Rakotovao ${ }^{1}$
}

\author{
${ }^{1}$ Department of Obstetrics and Gynecology, Soavinandriana Hospital Center, Faculty of Medicine Antananarivo, \\ Antananarivo, Madagascar \\ ${ }^{2}$ Department of Public Health, Faculty of Medicine, Antananarivo, Madagascar
}

Received: 24 January 2019

Accepted: 05 March 2019

\author{
*Correspondence: \\ Dr. Tanjona A. Ratsiatosika, \\ E-mail: ratsiatosika.tanjona@gmail.com
}

Copyright: (c) the author(s), publisher and licensee Medip Academy. This is an open-access article distributed under the terms of the Creative Commons Attribution Non-Commercial License, which permits unrestricted non-commercial use, distribution, and reproduction in any medium, provided the original work is properly cited.

\begin{abstract}
Background: Preeclampsia is a complication of pregnancy responsible for high rates of morbidity and mortality, particularly in Africa and Madagascar. The objective of present study was to assess patients' knowledge, attitudes and beliefs about pre-eclampsia in Madagascar.

Methods: This is an observational study on the knowledge, belief and attitudes of women seen at the Befelatanana Gynecology and Obstetrics Hospital and conducted by questionnaires from 1 December 2017 to 30 May 2018.

Results: During the study period, 102 patients agreed to answer our questionnaire. Terminology exists in the local language to describe convulsions and hypertension, but there were no terms that are specific to pregnancy. More than half of our patients knew preeclampsia. In $41 \%$ of cases, patients attributed excessive salt intake as a cause of high blood pressure during pregnancy and in $20 \%$ secondary to stress. Headache was the best-known symptom of patients. Signs of danger such as epigastric pain, genital bleeding, visual disturbances, convulsions and decreased sensation of fetal movements are not well known to patients. One-third did not know it was lethal. Regarding fetal complications, the occurrence of fetal death in utero was the best known. The majority of patients were aware that blood pressure measurements and urine dipstick testing were mandatory during pregnancy follow-up. To prevent preeclampsia, $46.07 \%$ thought that reducing salt intake would reduce the occurrence of preeclampsia.

Conclusions: Few patients are aware of preeclampsia, its danger signs and its complications, especially during prenatal consultation. This requires the improvement of knowledge of all health actor. Community health workers should receive basic and ongoing training to facilitate dialogue and information for pregnant and non-pregnant women in each society.
\end{abstract}

Keywords: Attitudes, Eclampsia, Hypertension, Nigeria, Perception, Pre-eclampsia, Seizures

\section{INTRODUCTION}

Preeclampsia is defined as a multisystem disorder characterized by high blood pressure (HBP); systolic blood pressure (SBP) $\geq 140 \mathrm{mmHg}$ and/or diastolic blood pressure $(\mathrm{DBP}) \geq 90 \mathrm{mmHg}$ ) and proteinuria $(>0.3 \mathrm{~g} / 24 \mathrm{~h}$ ) that occurs after 20 weeks of gestation and can be present as late as 7 weeks postpartum. ${ }^{1}$ Preeclampsia is one of the most common complications of pregnancy and continues being a leading cause of death (70000 to 80000/year) and 
maternal morbidity worldwide. ${ }^{2}$ It is responsible for high rates of morbidity and mortality, particularly in Africa. ${ }^{3}$

At the University Hospital of Gynecology and Obstetrics of Befelatanana, preeclampsia has an incidence of $3.3 \% .^{4}$ This is responsible for $41.7 \%$ maternal deaths due to preeclampsia in $2016 .^{5}$ Among preeclamptic patients, $4.9 \%$ had died and there was $50 \%$ perinatal mortality. Several parameters may explain this high mortality, but the major cause was delayed care before admission to hospital. ${ }^{4}$

The complications of preeclampsia have been shown to be due in part to a delay in the need for care. This would be due to a delay in the knowledge of the signs which should lead to being consulted, the delay due to the transport to facilitate the care. ${ }^{6}$

Patients were seen at the hospital only at the major complication stage. In this center, eclampsia was complicated by eclampsia in $45.77 \%$ of cases. ${ }^{4}$ Given the severity of this disease, it seems to us to know the attitude of patients to this potentially serious disease.

The objective of this study was to assess patients' knowledge, attitudes and beliefs about pre-eclampsia in Madagascar. An understanding of its parameters would be helpful in enabling a strategy to reduce maternal and perinatal mortality.

\section{METHODS}

This is an observational study carried out at the University Hospital Center of Obstetric Gynecology of Befelatanana Antananarivo Madagacar over a period of 6 months, from $1^{\text {st }}$ December 2017 to $30^{\text {th }}$ May 2018.

The hospital has a high activity rate. Every year, an average of 7,250 births are recorded in this center. It is a reference center of Antananarivo and surrounding cities in gynecology and obstetrics fields.

This hospital has 92 beds for patients hospitalized for obstetric reasons, 42 beds for gynecological causes, 24 beds reserved for resuscitation.

\section{Inclusion criteria}

- Authors included women who gave birth at least once and seen in the center during the study period.

\section{Exclusion criteria}

- Nulliparous and nulligested patients and patients who refused to respond to the survey were excluded.

A questionnaire on preeclampsia and its consequences translated into Malagasy was distributed. Authors studied:

- Maternal socio-demographic parameters
- Knowledge of preeclampsia

- Knowledge of the warning and danger signs of preeclampsia

- Knowledge of the complications of preeclampsia.

\section{Statistical analysis}

Quantitative variables are expressed on average and their standard deviations and qualitative variables as percentages.

Authors used the R software for the statistical analysis of the results.

\section{RESULTS}

During the study period, 102 patients agreed to answer present questionnaire.

Regarding the socio-demographic characteristics, the average age of our patients was $29.38 \pm 9.65$ years with extremes varying between 18 and 58 years. About twothirds of our patients were unemployed and women workers in the primary sector.

Three quarters of the cases were legally married. $42 \%$ of our patients were pregnant at the time of the survey (Table 1).

Table 1: Epidemiological characteristics of patients.

\begin{tabular}{|l|l|l|l|}
\hline Characteristic & & N & Percentage \\
\hline \multirow{5}{*}{ Occupation } & Housewife & 34 & 33.33 \\
\cline { 2 - 4 } & Primary sector & 34 & 33.33 \\
\cline { 2 - 4 } & Secondary sector & 28 & 27.45 \\
\cline { 2 - 4 } Pregnancy & Tertiary sector & 6 & 5.88 \\
\hline \multirow{5}{*}{ Family status } & Not pregnant & 10 & 9.80 \\
\hline & Pregnant & 42 & 41.17 \\
\hline & Postpartum & 50 & 49.01 \\
\hline & Single & 00 & 0.00 \\
\cline { 2 - 4 } & Concubine & 17 & 16.66 \\
\cline { 2 - 4 } & Maried & 77 & 75.49 \\
\cline { 2 - 4 } & Divorced & 8 & 7.84 \\
\hline
\end{tabular}

More than half of our patients $(54.90 \%)$ knew of preeclampsia. In $71.73 \%$ of cases, it was the entourage who informed the patients. There were no local names of preeclampsia and only $3.92 \%$ had a correct name. Eclampsia had no local name.

In only $15 \%$, patients knew that preeclampsia was a complication specific to pregnancy. In $41 \%$ of cases, patients attributed excessive salt intake as a cause of high blood pressure during pregnancy and $20 \%$ to stress (Table 2).

Of the patients who gave the responses, headache was the best-known symptom of patients $(83.33 \%)$. 
Signs of danger such as epigastric pain, genital bleeding, visual disturbances, convulsions and decreased sensation of fetal movements were not considered by the majority of patients who gave responses as signs of danger to the fetus. preeclampsia (Table 3). Regarding the complications of preeclampsia, maternal death was the best known maternal complication, however $38.24 \%$ did not know it was fatal. Regarding fetal complications, the occurrence of in utero fetal death was the best known $(68.62 \%)$ (Table 3).

Table 2: Information on pre-eclampsia.

\begin{tabular}{|c|c|c|c|}
\hline \multirow{3}{*}{ Knowledge of preeclampsia } & \multicolumn{3}{|c|}{$\mathbf{N}$} \\
\hline & Yes & 56 & $54.90 \%$ \\
\hline & No & 46 & $45.09 \%$ \\
\hline \multirow{3}{*}{ Source of information } & Radio & 1 & $02.17 \%$ \\
\hline & During antenatal care & 14 & $30.43 \%$ \\
\hline & Entourage & 33 & $71.73 \%$ \\
\hline \multirow{5}{*}{ Local name for preeclampsia } & Albimina & 36 & $35.29 \%$ \\
\hline & Miakatra tosidrà (HBP) & 9 & $08.82 \%$ \\
\hline & Preeclampsia & 4 & $03.92 \%$ \\
\hline & Tension & 3 & $02.94 \%$ \\
\hline & No answer & 50 & $49.01 \%$ \\
\hline \multirow{3}{*}{ Local designation of eclampsia } & Kirizy (convulsion) & 6 & $05.88 \%$ \\
\hline & Mifanintona (épilepsy) & 3 & $02.94 \%$ \\
\hline & No answer & 93 & $91.17 \%$ \\
\hline \multirow{2}{*}{ Is de novo preeclampsia a pathology induced by pregnancy? } & No & 86 & $84.32 \%$ \\
\hline & Yes & 16 & $15.68 \%$ \\
\hline \multirow{17}{*}{ Cause of hypertension during pregnancy } & Stress & 21 & $20.58 \%$ \\
\hline & Salt intake & 42 & $41.17 \%$ \\
\hline & Hypersodial diet & 2 & $01.96 \%$ \\
\hline & Physical fatigue & 3 & $02.94 \%$ \\
\hline & Emotional shock & 2 & $01.96 \%$ \\
\hline & Advanced maternal age & 1 & $00.98 \%$ \\
\hline & Alcohol & 2 & $01.96 \%$ \\
\hline & Coffee & 2 & $01.96 \%$ \\
\hline & Heredity & 3 & $02.94 \%$ \\
\hline & Malnutrition & 2 & $01.96 \%$ \\
\hline & Abnormal placentation & 1 & $00.98 \%$ \\
\hline & Insomnia & 1 & $00.98 \%$ \\
\hline & Overweight & 1 & $00.98 \%$ \\
\hline & Dietetary & 3 & $02.94 \%$ \\
\hline & High blood pressure & 1 & $00.98 \%$ \\
\hline & Allergy & 1 & $00.98 \%$ \\
\hline & No answer & 21 & $20.58 \%$ \\
\hline
\end{tabular}

On the other hand, in front of these signs the patient would consult a doctor (Table 4).

The majority of patients were aware that blood pressure measurements and urine dipstick test were mandatory (92.16\% and $91.11 \%$, respectively).

However, $20.58 \%$ of these patients did not have a blood pressure measurement during pregnancy and only $39.22 \%$ had undergone urine test during pregnancy.
Regarding the health worker who will have to follow the pregnancy, in only $22.54 \%$, the patients thought that the pregnancy should be followed by an obstetrician (Table $5)$.

To prevent preeclampsia, $46.07 \%$ thought that reducing salt intake would reduce the occurrence of preeclampsia.

Only one patient thought that taking aspirin would reduce the occurrence of preeclampsia (Table 6). 
Table 3: Danger signs of preeclampsia.

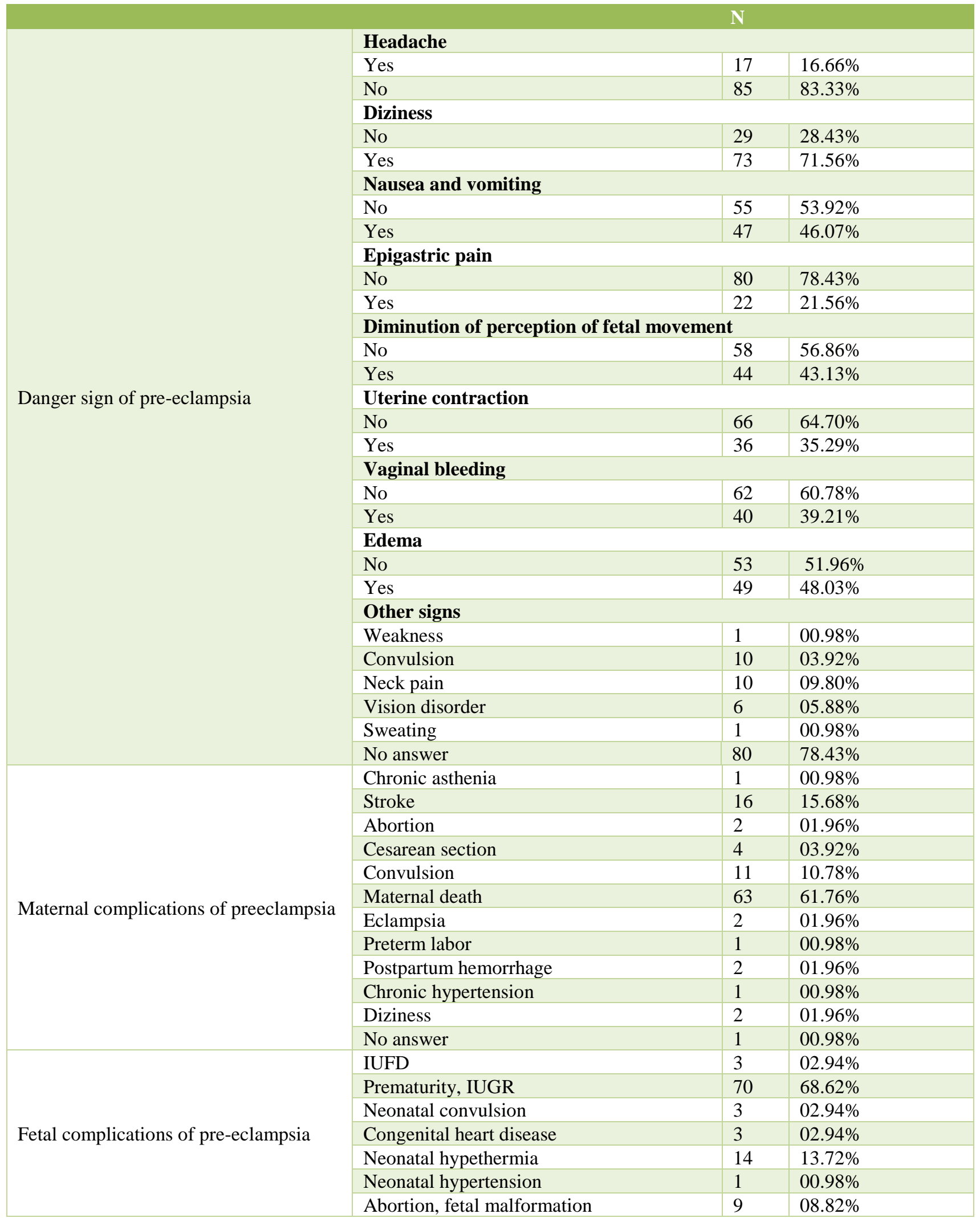


Table 4: Attitude at danger signs.

\begin{tabular}{|l|l|l|l|l|}
\hline & Expectative & Self-medication & Hospital & Tambavy \\
\hline Headache & $00(0.00 \%)$ & $1(00.98 \%)$ & $101(99.01 \%)$ & $00(0.00 \%)$ \\
\hline Dizziness & $00(0.00 \%)$ & $00(0.00 \%)$ & $102(100 \%)$ & $00(0.00 \%)$ \\
\hline Nausea & $00(0.00 \%)$ & $00(0.00 \%)$ & $102(100 \%)$ & $00(0.00 \%)$ \\
\hline Epigastric pain & $00(0.00 \%)$ & $00(0.00 \%)$ & $102(100 \%)$ & $00(0.00 \%)$ \\
\hline Diminution of fetal movement & $00(0.00 \%)$ & $00(0.00 \%)$ & $102(100 \%)$ & $00(0.00 \%)$ \\
\hline Uterine contraction & $00(0.00 \%)$ & $00(0.00 \%)$ & $102(100 \%)$ & $00(0.00 \%)$ \\
\hline Vaginal bleeding & $00(0.00 \%)$ & $00(0.00 \%)$ & $102(100 \%)$ & $00(0.00 \%)$ \\
\hline Edema & $00(0.00 \%)$ & $00(0.00 \%)$ & $99(97.05 \%)$ & $03(2.94 \%)$ \\
\hline
\end{tabular}

Table 5: Pregnancy monitoring.

\begin{tabular}{|c|c|c|c|}
\hline \multicolumn{2}{|l|}{ Question } & \multicolumn{2}{|l|}{$\mathbf{N}$} \\
\hline \multirow{2}{*}{ Is blood pressure measurement mandatory for each ANC? } & No & 8 & $07.84 \%$ \\
\hline & Yes & 94 & $92.16 \%$ \\
\hline \multirow{2}{*}{ Was the blood pressure taken during your ANC? } & No & 21 & $20.58 \%$ \\
\hline & Yes & 81 & $79.42 \%$ \\
\hline \multirow{2}{*}{ Is the urinary dipstick mandatory at each ANC? } & No & 9 & $08.82 \%$ \\
\hline & Yes & 93 & $91.11 \%$ \\
\hline \multirow{2}{*}{ Was the urinary dipstick performed during your ANC? } & No & 62 & $60.78 \%$ \\
\hline & Yes & 40 & $39.22 \%$ \\
\hline \multirow{4}{*}{ Which health worker will you see if you have high blood pressure during pregnancy? } & Any & 1 & $00.98 \%$ \\
\hline & Midwives & 31 & $30.39 \%$ \\
\hline & General practitioner & 47 & $46.07 \%$ \\
\hline & Obstetrician & 23 & $22.54 \%$ \\
\hline
\end{tabular}

Table 6: Prevention of preeclampsia.

\begin{tabular}{|l|l|l|l|}
\hline \multirow{5}{*}{} & Aspirin & 1 & $00.98 \%$ \\
\hline \multirow{4}{*}{$\begin{array}{l}\text { Prevention } \\
\text { of } \\
\text { preeclampsia }\end{array}$} & Medical follow-up & 4 & $03.92 \%$ \\
\hline \multirow{5}{*}{ Regular antenatal care } & 9 & $08.82 \%$ \\
\hline & Eviction of fatigue & 2 & $01.96 \%$ \\
\cline { 2 - 4 } & Go to the hospital & 3 & $02.94 \%$ \\
\hline & $\begin{array}{l}\text { Taking of pomegranate } \\
\text { juice }\end{array}$ & 1 & $00.98 \%$ \\
\cline { 2 - 4 } & Eviction of contraception & 1 & $00.98 \%$ \\
\cline { 2 - 4 } & Hypoproteic diet & 1 & $00.98 \%$ \\
\hline & Low-sodium diet & 47 & $46.07 \%$ \\
\hline & Rest & 6 & $05.88 \%$ \\
\hline & No answer & 18 & $17.64 \%$ \\
\hline
\end{tabular}

\section{DISCUSSION}

Through this study authors have found that patients do not know preeclampsia, its signs of danger and seriousness. This is identical to studies conducted in Nigeria, India and Pakistan. ${ }^{7-10}$ Information on this specific disease of pregnancy remains insufficient. The lack of education during prenatal consultations is marked in this study.

This is the first study done in Madagascar on knowledge of preeclampsia. Ratsiatosika et al, had already mentioned in a later study in the same center that this pathology was often associated with high maternofetal mortality and was often seen in hospital only at the stage of severe complication. ${ }^{4}$ Knowledge of women's attitudes towards preeclampsia would allow us to improve care.

The local name of preeclampsia does not exist. The search for albumin in the urine gave the name of preeclampsia to "alibiminina" in the community. This is not specific to preeclampsia but any hypertension with edema is called "alibiminina". Terminology exists for convulsion and hypertension in Malagasy ("mifanintona" and "miakatra tosidrà" respectively) but eclampsia did not have a local name. Patients confused eclampsia and epilepsy. This finding was identical to other studies in Africa and Asia. ${ }^{3,10-12}$ Only $15 \%$ of women knew that preeclampsia was a pathology specific to pregnancy.

In $71.73 \%$ of cases, it is the entourage that informs the patients. Only $30 \%$ were informed during the antenatal consultation about preeclampsia. The lack of prenatal consultation of quality and number explains this percentage. A study of preeclampsia in the center had shown an insufficient number of prenatal consultations in pre-hospitalized patients. ${ }^{4}$ Another study in the same center asserts that the poor monitoring of pregnancy resulting in an insufficient number of CPN exposed preeclampsia to a poor prognosis..$^{5}$ Soltani et al, had shown that parturients with a health education are better aware of the care and the right attitudes to take during 
and after pregnancy. ${ }^{13}$ Improving the monitoring of pregnancy with information and education of patients on pathologies that may occur during pregnancy would reduce maternal and neonatal morbidity and mortality in Madagascar.

In most developing countries, women and the community believe that high blood pressure during pregnancy is due to a stress of everyday life..$^{3,10-12}$ In India, Vidler et al, reported that dietary deficiency stress is the main cause cited by patients. ${ }^{10}$ In Mozambique, stress and conflict with the in-laws would be the causes according to the patients. $^{11}$ In Nigeria, depression and stress were considered to be the leading cause of preeclampsia. ${ }^{3}$ In Pakistan, stress and fatigue are reported to be the cause of the patients. ${ }^{12}$ In our population, apart from stress, salt intake is considered the cause of high blood pressure in $41 \%$ of cases. $84 \%$ of our population did not know that preeclampsia was a pregnancy-related condition. High maternal age, heredity, overweight and abnormal placentation may be the cause of preeclampsia reported by some patients. Other risk factors, such as the history of hypertension, pre-eclampsia, primiparity, primipaternity, and diabetes cited in the literature, are not known by patients. $^{14}$

In this study, headache and dizziness were the signs considered signs of severity experienced by women. This is identical to the literature. ${ }^{11,12}$ On the other hand, serious signs such as epigastric pain and visual blur were not known by the patients. These signs are recognized only by $21.56 \%$ and $5.88 \%$ respectively. This explains why all the preeclampsia seen in this center are already at an advanced stage. ${ }^{4}$ Convulsion was not considered a complication of preeclampsia in our population. In the literature, patients know that convulsion is a sign of gravity. ${ }^{3,10-12}$ This shows the inadequacy of information given to parturients during prenatal consultations. It is therefore necessary to improve prenatal care follow-up. It is not surprising to see the high frequency of eclampsia $(38.5 \%)$ at the Befelatanana Hospital Centre. ${ }^{4}$

Maternal mortality is the most feared complication by patients. Studies in Asia and Africa have reported the same finding.,10-12 Although the consequence of preeclampsia is fatal according to most patients, and almost all realize that hospitalization would be necessary in the event of a sign of severity, but this is not the case in practice. Ratsiatosika et al, reported that patients hospitalized for severe pre-eclampsia in this centre have never been hospitalized previously. ${ }^{4}$

According to these patients, specialized consultation would not be necessary. Only $22 \%$ consider that consultation by an obstetrician would be useful. There is a contradiction between the reality and the investigation that was conducted. They know that the existence of signs of gravity must lead them to the hospital, however, they are seen only in the stage of severe complication that is often lethal.
Regarding screening for preeclampsia, almost all patients are convinced that blood pressure measurements and urine dipstick test should be systematic during pregnancy. But in practice, $20 \%$ did not have a blood pressure test and $60 \%$ did not do the urine dipstick test. According to Mounier-Veiher et al, blood pressure should be taken systematically, and the urine test should be performed at least once a month. ${ }^{15}$ Prenatal monitoring in Madagascar should be improved in order to detect serious pathologies that may occur. to cause maternal vital prognosis. For prevention, patients believe that a dietary measure would reduce the frequency of preeclampsia. A low-protein diet would decrease proteinuria in some patients. A diet low in salt for some would reduce high blood pressure. This is identical to a study conducted in Nigeria. ${ }^{3}$ In Mozambique, early prenatal follow-up prevents the occurrence of pre-eclampsia. ${ }^{11}$ In India, eliminating the stress of daily life would prevent pre-eclampsia among patients. ${ }^{12}$ According to the WHO, home rest, restriction of dietary salt intake, supplementation with vitamin D, vitamin $C$ and vitamin $E$ is not a means of prevention of preeclampsia. In contrast, calcium supplementation in the malnourished and young patients and aspirin at high risk of are indicated to prevent preeclampsia. ${ }^{16}$

The monocentric nature, the low rate of participation of women in the survey constitutes the limits of this study which does not make it possible to extrapolate to the general population. Through this study, authors only surveyed women but husbands and the whole family could play a role in the perception of their patients. Large-scale surveys including men and family would provide a more generalized view of the Malagasy population's perception of preeclampsia.

\section{CONCLUSION}

This study has shed light on the knowledge of women about preeclampsia and its complications. Few patients are aware of this condition and its complications, especially during prenatal consultation. The signs of gravity are unknown by the patients. Although they know that the disease is life-threatening and that they need to consult if there are signs of danger, this is not the case in practice. Improving antenatal care by meeting the WHO standard would reduce maternal mortality from this disease. The education of pregnant women about signs, the risks of this disease should be carried out systematically by health workers during ANC. This requires the improvement of knowledge of all health actors. Community health workers should receive basic and ongoing training to facilitate dialogue and information for pregnant and non-pregnant women in each society.

\author{
Funding: No funding sources \\ Conflict of interest: None declared \\ Ethical approval: The study was approved by the \\ Institutional Ethics Committee
}




\section{REFERENCES}

1. Aronow WS. Hypertensive disorders in pregnancy. Ann Transl Med. 2017;5:266-71.

2. WHO, UNICEF, UNFPA, The World Bank and the United Nations Population Division. 2014. Trends in Maternal Mortality: 1990 to 2013. ISBN 978924 150722 6. CWorld Health Organization 2014.

3. Akeju DO, Vidler M, Oladapo OT, Sawchuck D, Qureshi R, von Dadelszen $\mathrm{P}$, et al. Community perceptions of pre-eclampsia and eclampsia in Ogun State, Nigeria: a qualitative study. Reprod Health. 2016;13(1):57.

4. Ratsiatosika AT, Razafimanantsoa E, Andriantoky VB, Ravoavison N, Hery AR, Boukerrou M, et al. Incidence and natural history of preeclampsia/ eclampsia at the university maternity of Antananarivo, Madagascar: high prevalence of the early-onset condition. J Matern Fetal Neonat Med. 2018:1-6.

5. Rakotomalala Z, Randriambololona DMA, Andriampanarivo HM, Rakotozanany B, Randriamaromanana ZN. Factors of poor prognosis in pre-eclampsia in Madagascar. Trop Med Health. 2016:78-82.

6. Thaddeus S, Maine D. Too far to walk: maternal mortality in context. Soc Sci Med. 1994;38(8):1091110 .

7. Asowa-Omorodion FI. Women's perceptions of the complications of pregnancy and childbirth in two Esan communities, Edo State. Nigeria Soc Sci Med. 1997;44(12):1817-24.

8. Hasan IJ, Nisar N. Womens' perceptions regarding obstetric complications and care in a poor fishing community in Karachi. J Pakistan Med Assoc. 2002;52:148.

9. Souza NL, Araujo ACPF, Azevedo GD, Jeronimo SMB, Barbosa LM, de Sousa NML. Maternal perception of premature birth and the experience of preeclampsia pregnancy. Rev Saude Publica. 2007;41(5):704.
10. Vidler M, Charantimath U, Katageri G, Ramadurg U, Karadiguddi C, Sawchuck D, et al. Community perceptions of pre-eclampsia in rural Karnataka State, India: a qualitative study. Reprod Health. 2016;13(1):45-53.

11. Boene H, Vidler M, Sacoor C, Nhama1A, Nhacolo $\mathrm{A}$, Bique $\mathrm{C}$, et al. Community perceptions of preeclampsia and eclampsia in southern Mozambique. Reprod Health. 2016;13(1):28-37.

12. Khowaja AR, Qureshi AR, Sheikh S, Zaidi S, Salam R, Sawchuck R. Community's perceptions of preeclampsia and eclampsia in Sindh Pakistan: a qualitative study. Reprod Health. 2016;13(1):39-44.

13. Soltani MS, Sakouhi M, Belguith Z, Ben Salem K, Gacem H, Bchir A. Assessment of mothers' knowledge of preventive pre- and post-natal care in the Tunisian Sahel. Public Health. 1999;11(2):20310.

14. Merviel P, Touzart L, Deslandes V, Delmas M, Coidaud M, Gondry J. Risk factor of preeclampsia in single pregnancy. J Gynecol Obstet Biol Reprod. 2008;37:477-82.

15. Mounier-Vehier C, Amar J, Boivin J, Denolle T, Fauvel J, Plu-Bureau G, et al. Hypertension and pregnancy. Expert consensus of the French Society of Hypertension, a subsidiary of the French Society of Cardiology. Presse Med. 2016.

16. The World Health Organization. WHO recommendations for prevention and treatment of pre-eclampsia and eclampsia. 2011. Available at: http://apps.who.int/iris/bitstream/10665/44703/1/978 9241548335_eng.pdf.

Cite this article as: Romuald $\mathrm{R}$, Ratsiatosika TA, Martial RA, Lantonirina RA, Ando-Miora R, Rakotovao AH. The women knowledge, attitude, and perceptions of pre-eclampsia and eclampsia in Madagascar. Int J Reprod Contracept Obstet Gynecol 2019;8:1233-9. 